\title{
Current Neural and Behavioral Dimensional Constructs Across Mood Disorders
}

\author{
Scott A. Langenecker • Rachel H. Jacobs • \\ Alessandra M. Passarotti
}

Published online: 24 June 2014

(C) Springer International Publishing AG 2014

\begin{abstract}
Our understanding of the underlying neurobiology for mood disorders is still limited. We present an integrated model for conceptualizing and understanding mood disorders drawing upon a broad literature. This integrated model of emotion processing and regulation incorporates the linguistic constructs of the Research Domain Criteria (RDoC) initiative. In particular, we focus on the positive valence domain/circuit (PVC), highlighting recent reward research and the negative valence domain/circuit (NVC), highlighting rumination. Furthermore, we also illustrate the Cognitive Control and Problem Solving (CCaPS) circuit, which is heavily involved in emotion regulation, as well as the default mode network (DMN) and interactions between circuits. We conclude by proposing methods for addressing challenges in the developmental study of mood disorders, including using high-risk design that incorporates risk for many disorders.
\end{abstract}

Keywords Depression $\cdot$ Bipolar $\cdot$ RDoC

\section{Introduction}

Neuroimaging and behavioral research in mood disorders is coalescing on a transdiagnostic, heterogeneous framework for

S. A. Langenecker $(\bowtie) \cdot$ R. H. Jacobs $\cdot$ A. M. Passarotti Department of Psychiatry, The University of Illinois at Chicago, 1601 W. Taylor St, Chicago, IL 60612, USA

e-mail: slangen@uic.edu

S. A. Langenecker $\cdot$ R. H. Jacobs $\cdot$ A. M. Passarotti Cognitive Neuroscience Center, The University of Illinois at Chicago, Chicago, IL, USA

R. H. Jacobs $\cdot$ A. M. Passarotti Institute for Juvenile Research, The University of Illinois at Chicago, Chicago, IL, USA understanding risk mechanisms leading to the expression of mental illness. The present review expands upon a conceptual framework for depression and related mood disorders offered by Phillips and colleagues [1,2], presents our integrative model for salience, valence, and executive networks in mood disorders, and adds detail for valence as well as explicit points of measurement and intervention. In addition to reviewing recent literature highlighting the relevance of positive and negative appraisal systems as they relate to dysfunction in mood disorders, we expand on the fundamental and interactive role of cognitive control in the expression of disease. We also touch upon recent research on the default mode network (DMN) as it relates to our model and circuit-based function.

This model for executive and salience networks in mood disorders (Fig. 1) offers a dynamic account of how multiple risk factors lead to mood disorders, including major depressive disorder (MDD) and bipolar disorder (BD). Similar to current diagnostic systems, individuals who meet criteria for MDD may have fundamentally divergent risk and protective factors leading to the same mood disorder. As a simple example, those with melancholic depression share few symptoms with individuals displaying atypical depression. As such, it is unwise to expect that the neural and behavioral bases supporting these subtypes would be the same or even similar. Our model is based on research denoting the brain circuits involved in emotional processing, cognitive control, and in the mind's "default" state, as well as the interactions between these circuits and burgeoning evidence that the behaviors and supporting circuitry evidenced in mood disorders are disrupted. We incorporate terminology used by the National Institutes of Mental Health (NIMH) Research Domain Criteria (RDoC) initiative, with a primary focus on salience networks (SN) including positive and negative valence circuits (PVC and NVC, respectively), cognitive systems including Cognitive Control and Problem Solving (CCaPS), and the DMN. 
Fig. 1 Model for executive and salience networks in mood disorders illustrating the preferential processing for positive stimuli (positive valence circuit; PVC) in healthy controls (HCs), which leads to a larger available repertoire of approach behaviors and enhanced regulatory capacities [through Cognitive Control and Problem Solving (CCaPS)] for appraisal, reappraisal, and the appropriate selection of alternative responses. In mood disorders, including major depressive disorder (MDD) and bipolar disorder (BD), the preferential strength of the PVC is diminished and so is $\mathrm{CCaPS}$ regulatory capacity, whereas the negative valence circuit (NVC) and related avoidance behaviors are strengthened and overrepresented. The PVC may be over- or under-utilized in BD and MDD, respectively

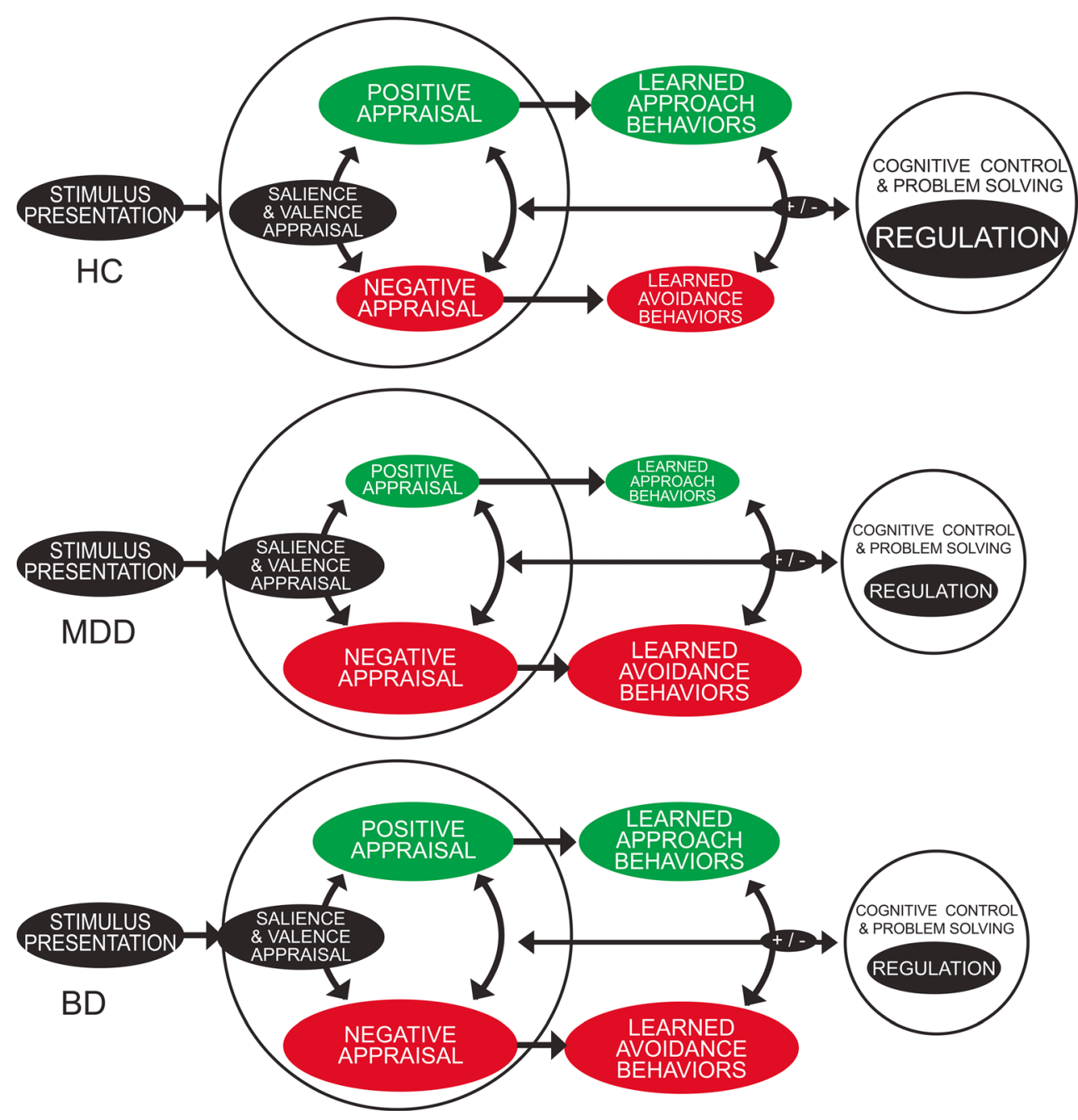

The PVC and NVC are rapid, efficient feature detectors that tag emotional, salient, and novel stimuli for further classification and processing [3-5]. These salience and valence processing steps help rapidly filter significant amounts of external and internal stimuli. In contrast, the CCaPS network is a slower, often more deliberate circuit that can engage in the modulation or regulation of emotion $[6,7 \bullet \bullet, 8]$. Moreover, there are intermediate stages of processing and response preparation where learned experience and habits can form prepotent response tendencies to certain types of external and internal stimuli and milieus. From a disease expression standpoint, overlearned response tendencies and emotional regulation need not all be dysfunctional. Environmental contributions and interactions between environment and genetic predispositions can vary the risk for and expression of disease dramatically. A mood disordered and healthy individual could have the exact same neural and behavioral profile, yet differ only in environmental stressors. This traditional stress-diathesis model is not well integrated into neuroimaging studies of mood disorders, nor has a multi-risk diathesis stress framework consistently been applied. The model presented here allows for fundamentally different loadings in the neural and behavioral risk factors observed in any mood disorders (AMD) relative to non-disordered groups.

The NVC and PVC consist of overlapping fronto-limbic networks supporting the detection of salience and valence processing [9]. The NVC is comprised of the ventral, central, and lateral amygdala, portions of the orbito-frontal cortex (OFC), and the posterior nucleus accumbens, which may also be more responsive to negative stimuli [10]. The NVC responds rapidly with low signal discrimination ability [11-13] and pre-activates learned response contingencies $[12,14,15]$. For example, the well-known fight or flight mechanism as a nearly automatic response contingency set that can be triggered in tens of milliseconds.

In parallel, the PVC comprises subcortical regions such as the nucleus accumbens, ventral pallidum, basal ganglia, and OFC [16, 17]. The PVC responds fairly rapidly, with low signal discrimination, and relies upon and is predicated toward developing learned contingencies. The PVC is somewhat subordinate to the $\mathrm{NVC}$, in that its responses and functioning can be subverted under threat, and it responds more slowly 
[18]. Depending on the valence, salience, and intensity of a given stimuli, appropriate response contingencies from shortand long-term memory are recalled and drawn upon [19]. Approach and/or avoidance responses are selected from amongst pre-potent responses, unless CCaPS is substantially engaged [20, 21]. Thus, the PVC and NVC reside in partially overlapping brain regions, but represent distinct processing streams $[9,10,22]$, and are thought to work in dynamic opposition.

The NVC and PVC interact with fronto-parietal circuits involved in cognitive control (CCaPS) and working memory (WM), which normally modulate these circuits and assist in selection of the appropriate response. The CCaPS circuit incorporates a number of regions involved in processing, regulating, and developing learning contingencies that can be incorporated into the present repertoire activated by PVC and NVC. In fact, one of the primary functions of this circuit is to minimize the complex processing that is required in the future [23]. The ability to distill complex environmental sets, integrate those with internal needs, and allow for rapid and efficient signal detection and response preparation, can place an individual at significant advantage over peers. Regions of the prefrontal cortex (PFC) organize and select behavior from response contingencies based upon prior knowledge, learning, and experience. Disruptions or damage to connections between the anterior cingulate cortex (ACC), including the dorsal ACC (dACC), and prefrontal regions have been found to be relevant to depression and diminished cognitive control [24]. Expectations and cost-benefit analyses also play a role in decision making, particularly from the medial and lateral OFC [25], providing an integration node between CCaPS and PVC/NVC. Furthermore, CCaPS can be inhibited by elicitation of emotional responses, either positive or negative [26]. One can conceptualize that NVC has hardwired capabilities that in a moment may interfere with and trump PVC and CCaPS function. A number of studies have investigated emotional interference effects, although these are methodologically complex and often confounded. We highlight interactions between the PVC, NVC, and $\mathrm{CCaPS}$ later in this review.

In addition to disruptions in task-related CCaPS and salience (PVC and NVC) circuits in mood disorders, there is also more recent mood disorder literature highlighting disruptions in the DMN, which is a "resting state" network devoted to internal thought and maintenance processes (e.g., memory consolidation). The DMN is a large-scale network of regions implicated in selforiented thought patterns [27-29], including rumination [30-32]. Other large-scale intrinsic networks that interact with the DMN include the CCaPS (executive) and PVC/ NVC (salience) [33]. Disrupted interactions within and between these networks are hypothesized to support the pathophysiology of MDD [34-36].

\section{Current Research on Negative Valence Domain/Circuit (NVC) Disruption in Mood Disorders}

Behavioral studies of NVC abnormalities in depression have often focused on mood congruent memory biases [37-39], negative processing biases [40-42], memory priming [43, 44], face emotion processing [45], and interference effects [46]. A majority of these studies indicate that depressed individuals have difficulty in correctly classifying facial stimuli $[45,47$, 48], and exhibit negative memory bias, which is one of the largest effect sizes in comparisons between depressed and non-depressed groups [49].

Functional MRI (fMRI) studies of NVC among individuals with mood disorders have focused heavily on the processing of emotion [50-52], emotionally evocative paradigms related to harsh/negative faces, complex visual scenes and images, films, autobiographical memories, social rejection, and semantic stimuli, some of which may be personally relevant [49, 53-59]. Disruptions to NVC include elevated amygdala, subgenual cingulate, and insula response to threat and diminished capability of those with mood disorders to regulate these responses. This domain is pertinent to our discussion because emotional appraisal and physiological reactivity to emotional stimuli and emotion induction are distinctly different in depressed than in control groups [11, $14,50]$. Furthermore, disruption in neurophysiological response to emotion stimuli is reversible with successful treatment $[50,63,64]$. In fact, the NVC is the most heavily researched in mood disorders and a number of reviews are available that cover these in detail [60-62]. As such, the NVC subdomains are not reviewed exhaustively here, rather we focus on one rapidly emerging aspect of the NVC, rumination.

A recent focus of study within the NVC is the construct of rumination, which falls within the Loss domain of the RDoC framework. Rumination is a perseverative negative thought pattern that involves passively dwelling on negative feelings [65]. The learned behavior and underlying neural signature of rumination represents a maladaptive habit. The development of this response style prior to full maturation of the PFC may result in a tendency to use avoidance strategies rather than the selection of responses requiring executive functioning such as problem-solving and approach-related behaviors. These patterns may result in a recurrent form of chronic depression that derails healthy emergence into adulthood.

Rumination impairs functional behavior by leading an individual to become stuck in thought and blocks the approach of action [66], leading to the proposal that rumination represents a transdiagnostic mechanism in the development of psychopathology $[67 \bullet \cdot 0$. Rumination remains elevated following remission from depression, is associated with lower levels of treatment response, prospectively predicts severity and duration of depressive episodes (for a review, see [65]), and mediates the 
effect of negative life events on subsequent affect [68]. Rumination hinders the reciprocal and dynamic interchange between cognitive and emotional states [69]. For example, rumination interferes with effective problem-solving [70] and instrumental behavior [71]. Preliminary studies have linked rumination to the DMN.

Research specific to the DMN, including studies with resting state fMRI (rs-fMRI) and task-based approaches, have evaluated the neural correlates of rumination among adults with active MDD [30-32]. Task-based fMRI studies have demonstrated correlations between regions of the DMN, particularly the dorsomedial PFC (dmPFC), and self-report rumination [30]. Additional studies have examined the neural correlates of rumination among healthy adults [30], and one study has linked functional connectivity of DMN to selfreport rumination among currently depressed adolescents [72•].

Rumination has also been explored in relation to loss anticipation within the NVC using monetary incentive delay (MID) tasks. For example, adults with remitted MDD (rMDD) demonstrated lower superior frontal gyrus (SFG) activation during loss anticipation and less inferior and SFG activation during loss outcomes [73•]. Self-report rumination was negatively correlated with SFG activation during loss outcomes in the rMDD group. The degree of SFG hypoactivation was associated with rumination, suggesting that abnormal prefrontal responses to loss may reflect a trait-like vulnerability to MDD. Prospective research conducted with 200 adolescents enrolled at age 12 or 13 years found that higher levels of baseline rumination were associated with decreases in selective attention and attentional switching at follow-up [74]. As such, rumination processes can detract from, interfere with, or undermine problem solving and control circuit processes.

\section{Current Research on Positive Valence Domain/Circuit (PVC) Disruption in Mood Disorders}

Reward and reward anticipation are recent foci areas when studying the PVC. Within this context, one important distinction is between reward anticipation or appraisal, that is, the "motivational" aspect (i.e., "wanting") of rewards, and response to delivered rewards, that is, the "consummatory" aspect (i.e., "liking") [75••]. Studying the relationship between reward systems and affect dysregulation is very promising, as positive affect is an emotional state elicited by reward and similar processes [76]. In recent years, behavioral studies of PVC disruptions in mood disorders have focused heavily on a deficient PVC model that, for example, conceptualizes anhedonia as disruption in reward consummatory processes, and apathy as disruption in anticipation of reward.
Patients with MDD tend to show apathy and anhedonia as well as hypoactivation of fronto-striatal circuits. Reward system abnormalities have also been found both in adult [77] and adolescent populations with MDD [78], leading to a characterization of "hypo-sensitivity to rewards" in MDD, with hypo-activation in ventral striatum(VS)/PVC $[79,80]$. In fact, a recent study with adolescents with MDD found reduced reward-related activity in the right caudal ACC, caudate, and OFC during high-risk/high-gain trials [81]. Similarly, [78] found decreased activation in the caudate and inferior OFC during both reward anticipation and response in 9-17 year olds with MDD. It is noteworthy that this pattern of dysfunction involving decreased striatal activation may be a promising candidate bio-marker for depression as it was found also in 10- to 14-year-old girls with high familial risk for depression, relative to a low-risk group, during anticipation and receipt of reward during an MID task [82]. PVC studies have shown the most progress in potentially predicting $\mathrm{BD}$ and distinguishing between MDD and BD [83].

\section{Current Research of Cognitive Control and Problem Solving (CCaPS) Disruption in Mood Disorders}

Behavioral studies of CCaPS on executive functioning, working memory (WM), and regulatory abnormalities in depression have focused more heavily on traditional neuropsychological tests of executive functioning. Executive functioning deficits have been reported in MDD and to a greater extent in $\mathrm{BD}$, although not consistently so $[45,84,85]$. Executive functioning measures have also been found to be predictive of treatment response in depressed patients [86-88] and of everyday functioning [89•]. Interestingly, studies of behavioral inhibition (BI) in depression have shown increased inhibition or withdrawal behavior in depressed patients $[90,91,92]$. Some studies suggest that these difficulties exist even in the remitted state [93], including amongst younger remitted individuals with an MDD history [94]. A recent meta-analysis suggests that even in rMDD, effect sizes for performance differences in CCaPS measures may be moderate to large, including the Trail Making Test B $(\mathrm{d}=0.48)$ and Stroop interference $(\mathrm{d}=0.74)[95 \bullet \bullet]$.

Recent fMRI studies have employed the Stroop Color Word Test [96], and variations of what has been called the Emotion Stroop [96-98]. WM paradigms have also been used widely, but they are slightly different than the regulatory difficulties in MDD [99, 100]. Measuring behavioral regulation, including response styles to a difficult cognitive task, may simulate real-life difficulties in behavioral and emotional regulation experienced by depressed patients [101], as evidenced by our and others' recent work [102, 103]. Our work with parametric Go/No-Go tasks $[6,103]$ suggests that regulatory mechanism may play a key role in the etiology, 
maintenance, and resolution of depression. More recently, a study in recurrent MDD demonstrated hypoactive right superior and dorsal medial PFC ( $\mathrm{dmPFC})$ for errors of commission relative to healthy comparison subjects [104•]. This hypoactivity was also present when visual negative feedback was given that a response was too slow for correct hits. In addition, more rapid normalization of the hypoactivation in the dACC extending into dmPFC was present in a subset of individuals who did not have recurrence of MDD within one year. A larger recent study with a Stroop task reported fronto-parietal hypoactivation in unmedicated MDD patients relative to healthy controls, in the context of atypically nondifferent group performance across color and incongruent trials $[105 \bullet]$.

\section{Current Research of Circuit Interactions in Mood Disorders}

The dynamic interaction of NVC (typically increased in mood disorders) and PVC (decreased in MDD, increased in $\mathrm{BD}$ ), and CCaPS (decreased in mood disorders) has been difficult to quantify in many studies. For example, if individuals are studied in active states of mood disorder, the circuits are already perturbed to a greater extent than what might or could be observed in the euthymic state, let alone the interactions between them. A shift away from PVC in depression might suggest a change in the regulatory skills in depressed patients [106, 107]. On the contrary, reduced behavioral regulation, associated with altered fronto-striatal activation, has been found in BD and MDD during response inhibition and WM tasks $[108,109,110]$. However, unlike MDD, BD is typically characterized by increased reward-seeking behavior [111]. Yet another pattern of relationship between reward-control systems is the one presented by individuals with "BI" who exhibit increased inhibition but also hypersensitivity of PVC, possibly as part of their hyper-vigilance to novelty and environmental cues [112•].

An important concept is that in internalizing disorders, disrupted appraisal of positive or negative contingencies may directly affect functioning of the CCaPS circuit. A promising way to look at the altered relationship between PVC and control processes is cognitive flexibility in the presence of reward contingencies. This is conceptually captured in the feedback arrows from CCaPS to PVC and approach behavior contingencies (Fig. 1). A probabilistic reversal learning study found that 6- to 17-year-old adolescents with BD showed worse accuracy than healthy controls. This occurred while learning the association between a reward and a stimulus within a pair of stimuli that were presented repeatedly, and while reversing their learned responses after the new reward object had been switched [113]. Similar results were found in adults with BD [114], suggesting developmental continuity in these deficits. Importantly, these dysfunction patterns seem specific to BD [115], in that impaired probabilistic reversal learning was found specifically in BD adolescents, while adolescents with MDD, severe mood dysregulation (SMD), and anxiety did not differ significantly from healthy adolescents.

Interesting results have also been obtained when looking at reward-related processes at the interface with decision-making in terms of a bias for immediate rewards. Studies with healthy adults found that hyperactivation of VS and reduced PFC activation correlated with preference for immediate rewards [116]. Developmental studies found that increased frontostriatal activation with development correlates with decreased delay discounting [117, 118]. Recent studies found that both adult patients with MDD [119] and with BD [120] exhibit steeper discounting during a delay discounting task relative to healthy controls. Altogether, these results suggest altered appraisal of future rewards in MDD and BD that may have implications for treatment approaches. Of course, it is possible that the neural mechanisms of discounting may be different across MDD and BD, and during different developmental stages.

These findings illustrate conceptual and practical interactions between PVC and CCaPS circuits, in addition to the more well-known NVC and CCaPS links described in prior studies. Parameterized designs that captured presence/absence of PVC/NVC priming and variable degrees of CCaPS may help toward understanding interactions between the circuits, and the dynamic irregularities that more closely approximate experiences of those with mood disorders. This would be particularly relevant to test in both active and remitted states.

\section{Developmental Considerations in the Study of Mood Disorders}

About $50 \%$ of adults with mental disorders have illness onset by age 14 years [121], suggesting that developmental models of mental illness are important in the evolution of psychiatric illness. The PFC and associative areas of the brain keep maturing until late adolescence [122] and are therefore more vulnerable to trauma and delayed or otherwise abnormal development. It is possible that there are developmental differences in the emergence of these circuits. Are there circuitbased strengths and in/efficiencies? If so, what are the interactions between these circuits? If there is developmental 
consistency in the aberrant functioning or interactions between these circuits, this neurophysiological consistency may help in the identification of predictors of illness or early onset. For instance, developmental studies show earlier development and more prominent influence of NVC and PVC in early adolescence and that through late-adolescence, as the PFC matures, CCaPS also improves and PVC decreases [123, 124]. In contrast, the NVC matures relatively early in development. Modulation of NVC and PVC by CCaPS may mature well into adulthood. Researchers have yet to fully understand the mechanisms functioning to derail healthy cognitive development in emerging internalizing disorders, specifically the interactions between NVC, PVC, CCaPS, and DMN circuits. We believe it is clear that these circuits and their interactions as they function in the development of mood disorders remain critical areas for future inquiry.

Along with potential developmental delays or dysfunctional interactions, there is other evidence that stable temperament patterns from early childhood related to NVC carry over with development and affect CCaPS by means of interacting with PVC. Some of the more informative developmental studies are with individuals with "BI", which denotes NVC hypersensitivity. These children present with vigilance to novelty, sensitivity to approach-withdrawal cues, and social withdrawal. Independent studies link reward hyper-responsivity to BI, adolescent anxiety, and dopamine gene variants [125]. Moreover, BI participants who had been assessed since infancy on measures of BI showed, relative to non-inhibited adolescents, increased striatal response patterns to social cues, such as during anticipation and receipt of positive and negative feedback from novel peers that were classified as being of high or low interest [112 $]$. This pattern suggests NVC overreactivity to salient social cues in BI. Similar patterns in BI were also found in a study with monetary rewards [126], possibly suggesting overactive PVC also. Overactive PVC, but only in response to gain versus loss, was also found in a pediatric population with generalized anxiety disorder; however, they did not show the BI profile of NVC over-reactivity to salient social cues [127]. These studies, while preliminary, suggest the need for additional longitudinal studies that may capture more precisely how early-life temperament can predict altered NVC and PVC responses in both social and nonsocial contexts, and in different populations such as inhibited versus disinhibited individuals.

\section{Summary, Integration, and Future Steps}

The present review highlights critical crossroads and future directions for mood disorders research. We highlight conceptual challenges toward understanding the dynamic role of PVC and NVC, their interactions with CCaPS circuits, and the relationship of these circuits with the DMN. These circuits have a basis in the psychological, theoretical, and animal literature, and are borne out in brain imaging, lesion, and related studies, including functional connectivity analyses. Finally, these circuits are encapsulated within the RDoC framework of the NIMH, the goal of which is to provide dimensional targets for treatment and measurement of posttreatment change.

These circuits also provide an opportunity to conceptualize variations within disorders such as MDD, as well as phases of $\mathrm{BD}$, and potential differences between MDD and BD. A substantial number of studies suggest increased NVC activation in MDD and BD groups. A potentially non-overlapping set within each group also exhibits diminished CCaPS function, which is related to treatment outcome, potential for relapse, and degree of life functioning. In contrast to these relative similarities in $\mathrm{NVC}$ and $\mathrm{CCaPS}$ dysfunction, initial studies suggest some amount of dissociation in the PVC system across mood disorder groups. A substantial proportion of those with BD exhibit PVC hypersensitivity, whereas a substantial number of those with MDD exhibit hypoactivation.

An important challenge for consideration is the development of these systems through childhood, adolescence, and young adulthood. Evaluating these circuits, the interactions between them, and the impact upon behavior requires careful designs that incorporate parametric evaluations of the presence/absence of NVC/PVC challenge and with and without significant involvement of the CCaPS. To do so, future models must incorporate substantial variability in the amount and degree of development of these circuits. For example, there is evidence that normative adolescent development results in relative dominance of NVC and PVC over CCaPS in childhood that is reversed for most as they transition into mid to late adolescence and adulthood. A delay in this transition may be difficult to characterize and quantify, and to some extent may overlap substantially in ill, at-risk, and no-risk groups. This critical window is an optimal area for study focus and primary and secondary prevention.

Finally, high-risk designs are one key area of continued study that can be successfully pursued using the proposed model. We can optimize the identifiable and measurable neural markers that can differentiate between different illnesses, and subsequently predict the illness progression. For example, one novel study [128•• ] identified a neurophysiological marker (i.e., elevated at-rest activity in left mid-frontal EEG) that prospectively predicted conversion from cyclothymia or BD Type II to BD Type I over a 4.7-year follow-up. It will also be fruitful to consider the extent to which neural and behavioral markers are shared across a number of illnesses. There is reason to suspect that high-risk studies for substance abuse and for MDD and BD might recruit from the same high-risk populations, allowing for pooling of resources and enhanced power. Such multi-risk group designs fit well into the RDoC 
framework and the highlighted circuits within our model of CCaPS, NVC, and PVC dysfunction in mood disorders.

Acknowledgment SAL was supported by MH 081911 and MH 101487. RHJ was supported by UL1TR000050. AMP was supported by MH 101487. The authors would like to thank Ms. Alyssa Barba for her assistance with this manuscript.

\section{Compliance with Ethics Guidelines}

Conflict of Interest Scott Langenecker, Rachel Jacobs and Alessandra Passarotti declare no conflicts of interest.

Human and Animal Rights and Informed Consent This article does not contain any studies with human or animal subjects performed by the authors.

\section{References}

Papers of particular interest, published recently, have been highlighted as:

- Of importance

•- Of major importance

1. Phillips M, Drevets W, Rauch S, Lane R. Neurobiology of emotion perception II: implications for major psychiatric disorders. Biol Psychiatry. 2003;54:515-28.

2. Phillips ML, Ladouceur CD, Drevets WC. A neural model of voluntary and automatic emotion regulation: implications for understanding the pathophysiology and neurodevelopment of bipolar disorder. Mol Psychiatry. 2008;19:833-57.

3. Servan-Schreiber D, Perlstein WM. Selective limbic activation and its relevance to emotional disorders. Cogn Emot. 1998;12: 331-52.

4. Ohman A, Soares J. Emotional conditioning to masked stimuli: expectancies for aversive outcomes following nonrecognized fearrelevant stimuli. J Exp Psychol. 1998;127:69-82.

5. Gerber AJ, Posner J, Gorman D, Colibazzi T, Yu S, Wang Z, et al. An affective circumplex model of neural systems subserving valence, arousal, and cognitive overlay during the appraisal of emotional faces. Neuropsychologia. 2008;46: 2129-39.

6. Langenecker SA, Caveney AF, Giordani B, Young EA, Nielson KA, Rapport LJ, et al. The sensitivity and psychometric properties of a brief computer-based cognitive screening battery in a depression clinic. Psychiatry Res. 2007;152:143-54.

7.• Pizzagalli DA. Frontocingulate dysfunction in depression: toward biomarkers of treatment response. Neuropsychopharmacol Rev. 2011;36:183-206. This is a thorough and critical review article that highlights the important role of the rostral anterior cingulate and dorsal medial prefrontal cortex in mood disorders. It emphasizes cross-modality and paradigm relationships between functioning and activation of this region with treatment response.

8. Nurnberger Jr JI, Blehar MC, Kaufmann CA, York-Cooler C, Simpson SG, Harkavy-Friedman J, et al. Diagnostic interview for genetic studies. Rationale, unique features, and training. NIMH Genetics Initiative. Arch Gen Psychiatry. 1994;51: 849-59.
9. Aggleton JP. The amygdala: neurobiological aspects of emotion, memory, and mental dysfunction. New York: Wiley-Liss; 1992.

10. Bench C, Friston K, Brown R, Scott L, Frackowiak R, Dolan R. The anatomy of melancholia: focal brain abnormalities of cerebral blood flow in major depression. Psychol Med. 1992;22:607-15.

11. Kumari V, Mittersciffthaler M, Teasdale J, Malhi G, Brown R, Giampietro V, et al. Neural abnormalities during cognitive generation of affect in treatment-resistant depression. Biol Psychiatry. 2003;54:777-91.

12. Paradiso S, Johnson D, Andreasan N, O'Leary D, Watkins G, Ponto L, et al. Cerebral blood flow changes associated with attribution of emotional valence to pleasant, unpleasant, and neutral visual stimuli in a PET study of normal subjects. Am J Psychiatr. 1999;156:1618-29.

13. Wilner P, Bloom FE, Kupfer DJ. Dopaminergic mechanisms in depression and mania. In: Psychopharmacology: the fourth generation of progress. New York: Raven Press; 1995. pp. 921-31.

14. Ketter TA, Andreason PJ, George MS, Lee C, Gill DS. Anterior paralimbic mediation of procaine-induced emotional and psychosensory experiences. Arch Gen Psychiatry. 1996;53:59-69.

15. Cohen RM, Weingartner H, Smallberg SA, Pickar D, Murphy DL. Effort and cognition in depression. Arch Gen Psychiatry. 1982;39: 593-8.

16. Rolls ET, Hornak J, Wade D, McGrath J. Emotion-related learning in patients with social and emotional changes associated with frontal lobe damage. J Neurol Neurosurg Psychiatry. 1994;57: 1518-24.

17. Siegle GJ, Steinhauer SR, Thase ME, Stenger A, Carter CS. Can't shake that feeling: event-related fMRI assessment of sustained amygdala activity in response to emotional information in depressed individuals. Biol Psychiatry. 2002;51:693-707.

18. Choi JM, Padmala S, Spechler P, Pessoa L. Pervasive competition between threat and reward in the brain. Soc Cogn Affect Neurosci. 2013:1-14.

19. Scott S, Young A, Calder A, Hellawell D, Aggleton J, Johnson M. Impaired auditory recognition of fear and anger following bilateral amygdala lesions. Nature. 1997;385:254-7.

20. Miller E, Lewis P. Recognition memory in elderly patients with depression and dementia: a signal detection analysis. J Abnorm Psychol. 1977;86:84-6.

21. Rush AJ, Laux G, Giles DE, Jarrett RB, Weissenburger J, Feldman-Koffler F, et al. Clinical characteristics of outpatients with chronic major depression. J Affect Disord. 1994;34:25-32.

22. Austin M-P, Mitchell P, Wilhelm K. Melancholic depression: a pattern of frontal cognitive impairment. Psychol Med. 1999;29: 73-85.

23. Kaufman D. Thinking, fast and slow. New York: Farrar, Straus and Giroux; 2011.

24. Konishi S, Nakajima K, Uchida I, Kameyama M, Nakahara K, Sekihara K, et al. Transient activation of inferior prefrontal cortex during cognitive set shifting. Nat Neurosci. 1998;1:80-4.

25. Rolls E. The orbitofrontal cortex and reward. Cereb Cortex. 2000;10:284-94.

26. Harlé KM, Shenoy P, Paulus MP. The influence of emotions on cognitive control: feelings and beliefs-where do they meet? Front Hum Neurosci. 2013;7:508.

27. Greicius MD, Krasnow B, Reiss AL, Menon V. Functional connectivity in the resting brain: a network analysis of the default mode hypothesis. Proc Natl Acad Sci U S A. 2003;100:470-8.

28. Sheline YI, Barch D, Price JL, Rundle MM, Vaishnavi SN, Snyder AZ, et al. The default mode network and self-referential processes in depression. Proc Natl Acad Sci U S A. 2009;106:1942-7.

29. Johnson MK, Nolen-Hoeksema S, Mitchell KJ, Levin Y. Medial cortex activity, self-reflection and depression. Soc Cogn Affect Neurosci. 2009;4:313-27. 
30. Cooney RE, Joormann J, Eugene F, Dennis EL, Gotlib IH. Neural correlates of rumination in depression. Cogn Affect Behav Neurosci. 2010;10:470-8.

31. Berman MG, Peltier S, Nee DE, Kross E, Deldin PJ, Jonides J. Depression, rumination and the default network. Soc Cogn Affect Neurosci. 2011;6(5):548-55.

32. Hamilton JP, Furman DJ, Chang C, Thomason ME, Dennis E, Gotlib IH. Default-mode and task-positive network activity in major depressive disorder: implications for adaptive and maladaptive rumination. Biol Psychiatry. 2011;70:327-33.

33. Seeley WW, Menon V, Schatzberg AF, Keller J, Glover GH, Kenna H, et al. Dissociable intrinsic connectivity networks for salience processing and executive control. J Neurosci Off J Soc Neurosci. 2007;27:2349-56.

34. Sheline YI, Price J, Yan Z, Mintun MA. Resting-state functional MRI in depression unmasks increased connectivity between networks via the dorsal nexus. Proc Natl Acad Sci U S A. 2010;107: $11020-5$.

35. Greicius MD, Flores BH, Menon V, Glover GH, Solvason HB, Kenna $\mathrm{H}$, et al. Resting-state functional connectivity in major depression: abnormally increased contributions from subgenual cingulate cortex and thalamus. Biol Psychiatry. 2007;62:429-37.

36. Broyd SJ, Demanuele C, Debener S, Helps SK, James CJ, Sonuga-Barke EJ. Default-mode brain dysfunction in mental disorders: a systematic review. Neurosci Biobehav Rev. 2009;33: 279-96.

37. Gotlib IH, Krasnoperova E, Yue DN, Joormann J. Attentional biases for negative interpersonal stimuli in clinical depression. J Abnorm Psychol. 2004;113:127-35.

38. Gotlib IH, Traill SK, Montoya RL, Joormann J, Chang K. Attention and memory biases in the offspring of parents with bipolar disorder: indications from a pilot study. J Child Psychol Psychiatry. 2005;46:84-93.

39. Rude SS, Wentzlaff RM, Gibbs B, Vane J, Whitney T. Negative processing biases predict subsequent depressive symptoms. Cogn Emot. 2002; 16:423-40.

40. Danion JM, Kauffmann-Muller F, Grange D. Affective valence of words, explicit and implicit memory in clinical depression. J Affect Disord. 1995;34:227-34.

41. Danion JM, Willard-Schroeder D, Zimmermann MA, Grange D, Schlienger JL, Singer L. Explicit memory and repetition priming in depression, preliminary findings. Arch Gen Psychiatry. 1991;48:707-11.

42. Watkins PC, Mathews A, Williamson DA, Fuller RD. Moodcongruent memory in depression - emotional priming or elaboration. J Abnorm Psychol. 1992;101:581-6.

43. Bradley BP, Mogg K, Millar N, White J. Selective processing of negative information: effects of clinical anxiety, concurrent depression, and awareness. J Abnorm Psychol. 1995;104:532-6.

44. Mogg K, Bradley BP, Williams R, Mathews A. Subliminal processing of emotional information in anxiety and depression. $\mathrm{J}$ Abnorm Psychol. 1993;102:304-11.

45. Langenecker S, Bieliauskas LA, Rapport LJ, Zubieta J-K, Wilde EA, Berent S. Face emotion perception and executive functioning deficits in depression. J Clin Exp Neuropsychol. 2005;27:320-33.

46. Fales CL, Barch DM, Rundle MM, Mintun MA, Snyder AZ, Cohen JD, et al. Altered emotional interference processing in affective and cognitive-control brain circuitry in major depression. Biol Psychiatry. 2008;63:377-84.

47. Bouhuys AL, Geerts E, Mersch PPA, Jenner JA. Nonverbal interpersonal sensitivity and persistence of depression: perception of emotions in schematic faces. Psychiatry Res. 1996;64:193-203.

48. Bouhuys AL, Geerts E, Gordijn MCM. Depressed patients' perceptions of facial emotions in depressed and remitted states are associated with relapse: a longitudinal study. J Nerv Ment Dis. 1999;187:595-602.
49. Hsu DT, Langenecker SA, Kennedy S, Zubieta J, Heitzeg MM. fMRI BOLD responses to negative stimuli in the prefrontal cortex are dependent on levels of recent negative life stress in major depressive disorder. Psychiatry Res. 2010;183:202-8.

50. Kalin N, Davidson R, Irwin W, Warner G, Orendi J, Sutton S, et al. Functional magnetic resonance imaging studies of emotional processing in normal and depressed patients: effects of venlafaxine. $\mathrm{J}$ Clin Psychiatry. 1997;58:32-9.

51. Wright CI, Fischer H, Whalen PJ, McInerney SC, Shin LM, Rauch SL. Differential prefrontal cortex and amygdala habituation to repeatedly presented emotional stimuli. NeuroReport Rapid Commun Neurosci Res. 2001;12:379-83.

52. Whalen PJ. Masked presentation of emotional facial expressions modulate amygdala activity without explicit knowledge. J Neurosci. 1998;18:411-9.

53. Fossati P, Hevenor S, Graham SJ, Grady C, Keightley ML, Craik F, et al. In search of the emotional self: an fMRI study using positive and negative emotional words. Am J Psychiatr. 2003;160:1938-45.

54. George MS, Ketter T, Gill D, Haxby J, Ungerleider L, Herscovitch $\mathrm{P}$, et al. Brain regions involved in recognizing facial emotion or identity: an oxygen-15 PET study. J Neuropsychiatry Clin Neurosci. 1993;5:384-94.

55. George MS, Ketter TA, Parekh PI, Rosinsky N, Ring H, Casey BJ, et al. Regional brain activity when selecting a response despite interference: an H 215 O PET study of the Stroop and an emotional Stroop. Hum Brain Mapp. 1994;1:194-209.

56. Silk JS, Siegle G, Hwa Lee K, Nelson EE, Stroud LR, Dahl RE. Increased neural response to peer rejection associated with adolescent depression and pubertal development. Soc Cogn Affect Neurosci.

57. Bertocci MA, Bebko GM, Mullin BC, Langenecker SA, Ladouceur CD, Almeida JRC, et al. Abnormal anterior cingulate cortical activity during emotional n-back task performance distinguishes bipolar from unipolar depressed females. Psychol Med. 2012;42:1417-28.

58. Mitterschiffthaler MT, Williams SC, Walsh ND, Cleare AJ, Donaldson C, Scott J, et al. Neural basis of the emotional Stroop interference effect in major depression. Psychol Med. 2008;38: 247-56.

59. Siegle GJ, Thompson W, Carter CS, Steinhauer SR, Thase ME. Increased amygdala and decreased dorsolateral prefrontal BOLD responses in unipolar depression: related and independent features. Biol Psychiatry. 2007;61:198-209.

60. Phan KL, Wager T, Taylor SF, Liberzon I. Functional neuroanatomy of emotion: a meta-analysis of emotion activation studies in PET and fMRI. NeuroImage. 2002;16:331-48.

61. Taylor SF, Kang J, Brege IS, Tso IF, Hosanagar A, Johnson TD. Meta-analysis of functional neuroimaging studies of emotion perception and experience in schizophrenia. Biol Psychiatry. 2012;71:136-45.

62. Groenewold NA, Opmeer EM, de Jonge P, Aleman A, Costafreda $\mathrm{S}$. Emotional valence modulates brain functional abnormalities in depression: evidence from a meta-analysis of fMRI studies. Neurosci Biobehav Rev. 2013;37:152-63.

63. Sheline YI, Barch DM, Donnelly J, Ollinger J, Snyder AZ, Mintun MA. Increased amygdala response to masked emotional faces in depressed subjects resolves with antidepressant treatment: an fMRI study. Biol Psychiatry. 2001;50:651-8.

64. Brody AL, Saxena S, Stoessel P, Gillies LA, Fairbanks LA, Alborzian S, et al. Regional brain metabolic changes in patients with major depression treated with either paroxetine or interpersonal therapy: preliminary findings. Arch Gen Psychiatr Spec Issue. 2001;58:631-40.

65. Nolen-Hoeksema S, Wisco BE, Lyubomirsky S. Rethinking rumination. Perspect Psychol Sci. 2008;3:400-24. 
66. Watkins ER. Constructive and unconstructive repetitive thought. Psychol Bull. 2008;134:163-206.

67.• Nolen-Hoeksema S, Watkins ER. A heuristic for developing transdiagnostic models of psychopathology explaining multifinality and divergent trajectories. Perspect Psychol Sci. 2011;6:589-609. Discusses transdiagnostic processes as they relate to intermediate phenotypes with attention to concepts such as multifinality. Uses rumination as an example of a transdiagnostic risk factor for psychopathology.

68. Moberly NJ, Watkins ER. Ruminative self-focus, negative life events, and negative affect. Behav Res Ther. 2008;46:1034-9.

69. Nolen-Hoeksema S, Morrow J. A prospective study of depression and posttraumatic stress symptoms after a natural disaster: the 1989 Loma Prieta Earthquake. J Pers Soc Psychol. 1991;61: 115-21.

70. Watkins E, Moulds M. Distinct modes of ruminative self-focus: impact of abstract versus concrete rumination on problem solving in depression. Emotion. 2005;5:319-28.

71. Lyubomirsky S, Nolen-Hoeksema S. Self-perpetuating properties of dysphoric rumination. J Pers Soc Psychol. 1993;65:339-49.

72. Connolly CG, Wu J, Ho TC, Hoeft F, Wolkowitz O, Eisendrath S, et al. Resting-state functional connectivity of subgenual anterior cingulate cortex in depressed adolescents. Biol Psychiatry. 2013;74:898-907. Recent paper exploring connectivity of the subgenual anterior cingulate cortex among depressed adolescents as it relates to rumination.

73. Schiller CE, Jared Minkel J, Smoski MJ, Dichter GS. Remitted major depression is characterized by reduced prefrontal cortex reactivity to reward loss. J Affect Disord. 2013;151:756-62. Recent paper examining responses to reward among a population of adults with $r M D D$. Rumination was negatively correlated with superior frontal gyrus activation during loss outcomes in the rMDD group.

74. Connolly SL, Wagner CA, Shaperoa BG, Pendergast LL, Abramson LY, Alloy LB. Rumination prospectively predicts executive functioning impairments in adolescents. J Behav Ther Exp Psychiatry. 2014;45:46-56.

75.• Haber SN, Knutson B. The reward circuit: linking primate anatomy and human imaging. Neuropsychopharmacology. 2010;35:4 26. Excellent review on reward circuits that links primate anatomy and human brain imaging studies. This comprehensive review discusses cortical and subcortical brain regions involved in reward-related processes, as well as connectivity between these regions that creates a complex neural network involved in different aspects of reward processing.

76. Forbes EE, Dahl R. Neural systems of positive affect: relevance to understanding child and adolescent depression? Dev Psychopathol. 2005;17:827-50.

77. Knutson B, Bhanji JP, Cooney RE, Atlas LY, Gotlib IH. Neural responses to monetary incentives in major depression. Biol Psychiatry. 2008;63:686-92.

78. Forbes EE, May C, Siegle GJ, Ladouceur CD, Ryan ND, Carter $\mathrm{CS}$, et al. Reward-related decision-making in pediatric major depressive disorder: an fMRI study. J Child Psychol Psychiatry. 2006;47:1031-40.

79. Forbes EE, Hariri A, Martin SL, Silk JS, Moyles DL, Fisher PM, et al. Altered striatal activation predicting real-world positive affect in adolescent major depressive disorder. Am J Psychiatry. 2009;166:64-73.

80. Zhanga W, Chang S, Guo L, Zhanga K, Wang J. The neural correlates of reward-related processing in major depressive disorder: a meta-analysis of functional magnetic resonance imaging studies. J Affect Disord. 2013;151:531-9.

81. Shad M, Bidesi AP, Chen L, Ernst M, Rao U. Neurobiology of decision making in depressed adolescents: a functional magnetic resonance imaging study. J Am Acad Child Adolesc Psychiatry. 2011;50:612-21.

82. Gotlib IH, Hamilton JP, Cooney RE, Singh MK, Henry ML, Joormann J. Neural processing of reward and loss in girls at risk for major depression. Arch Gen Psychiatry. 2010;67:380-7.

83. Diler RS, de Almeida JRC, Ladouceur C, Birmaher B, Axelson D, Phillips ML. Neural activity to intense positive versus negative stimuli can help differentiate bipolar disorder from unipolar major depressive disorder in depressed adolescents: a pilot fMRI study. Psychiatry Res Neuroimaging. 2013;214:277-84.

84. Cornell DG, Saurex R, Berent S. Psychomotor retardation in melancholic and nonmelancholic depression: cognitive and motor components. J Abnorm Psychol. 1984;932:150-7.

85. Neu P, Kiesslinger U, Schlattmann P, Reischies FM. Time-related cognitive deficiency in four different types of depression. Psychiatry Res. 2001;103:237-47.

86. Dunkin JJ, Leuchter AF, Cook IA, Kasl-Godley JE, Abrams M, Rosenberg-Thompson S. Executive dysfunction predicts nonresponse to fluoxetine in major depression. J Affect Disord. 2000;60:16-23.

87. Jones BP, Henderson M, Welch CA. Executive functions in unipolar depression before and after electroconvulsive therapy. Int $\mathrm{J}$ Neurosci. 1988;38:287-287.

88. Kampf-Sherf O, Zlotogorski Z, Gilboa A, Speedie L, Lereya J, Rosca P, et al. Neuropsychological functioning in major depression and responsiveness to selective seretonin reuptake inhibitors antidepressants. J Affect Disord. 2004;82:453-9.

89. Ryan KA, Vederman A, McFadden EM, Weldon AL, Kamali M, Langenecker SA, et al. Differential executive functioning performance by phase of bipolar disorder. Bipolar Disord. 2012;14:52736. This paper shows that executive functioning skills may vary based upon phases of bipolar disorder.

90. Johnson SL, Turner RJ, Iwata N. BIS/BAS levels and psychiatric disorder: an epidemiological study. J Psychopathol Behav Assess. 2003;25:25-36.

91. Leen-Feldner EW, Zvolensky MJ, Feldener MT, Lelguen C. Behavioral inhibition: relation to negative emotion reguation and reactivity. Personal Individ Differ. 2004;36:1235-47.

92. Farvolden P, Bagby RM. Behavioral activation and inhibition systems, the five factor model and their association with depression severity and response to treatment. J Affect Disord. 2004;78: S73-S73.

93. Weiland-Fiedler P, Erickson K, Waldeck T, Luckenbaugh DA, Pike D, Bonne O, et al. Evidence for continuing neuropsychological impairments in depression. J Affect Disord. 2004;82:253-8.

94. Kyte ZA, Goodyear I, Sahakian BJ. Selected executive skills in adolescents with recent first episode major depression. J Child Psychol Psychiatry. 2004;46:995-1005.

95.•• Bora E, Harrison BJ, Davey C, Yücel M, Pantelis C. Metaanalysis of volumetric abnormalities in cortico-striatal-pallidalthalamic circuits in major depressive disorder. Psychol Med. 2011;42:671-81. This is a meta-analysis of mood disorderrelated structural abnormalities in cortical, striatal, pallidum, and thalamic regions.

96. George MS, Ketter T, Parekh P, Rosinsky N, Ring H, Pazzaglia P, et al. Blunted left cingulate activation in mood disorder subjects during a response interference task (the Stroop). J Neuropsychiatry Clin Neurosci. 1997;9:55-63.

97. Videbech P, Ravnkilde B, Gammelgaard L, Egander A, Clemmensen K, Rasmussen N, Gjedde A, Rosenberg R. The Danish PET/depression project: performance on Stroop's test linked to white matter lesions in the brain. Psychiatry Res Neuroimaging. 2004;130:117-30.

98. Siegle G, Steinhauer S, Carter C, Thase M. Sustained processing on the Stroop task in depression. Supplement 1 ed, Blackwell Publishing; 2003. pp. S79-S79. 
99. Barch DM, Sheline YI, Csernansky JG, Snyder AZ. Working memory and prefrontal cortex dysfunction: specificity to schizophrenia compared with major depression. Biol Psychiatry. 2003;53:376-84.

100. Harvey PO, Fossati P, Pochon JB, Levy R, LeBastard G, Leheriey $\mathrm{S}$, et al. Cognitive control and brain resources in major depression: an fMRI study using the n-back task. NeuroImage. 2005;26:860-9.

101. Hooley JM, Gruber SA, Scott LA, Hiller JB, Yurgelun-Todd DA. Activation in dorsolateral prefrontal cortex in response to maternal criticism and praise in recovered depressed and healthy control participants. Biol Psychiatry. 2005;57:809-12.

102. Holmes AJ, Macdonald A, Carter CS, Barch DM, Stenger VA, Cohen JD. Prefrontal functioning during context processing in schizophrenia and major depression: an event-related fMRI study. Schizophr Res. 2005;76:199-206.

103. Langenecker SA, Kennedy SE, Guidotti LM, Briceno EM, Own LS, Hooven T, et al. Frontal and limbic activation during inhibitory control predicts treatment response in major depressive disorder. Biol Psychiatry. 2007;62:1272-80.

104. Nixon NL, Liddle PF, Worwood G, Liotti M, Nixon E. Prefrontal cortex function in remitted major depressive disorder. Psychol Med. 2013;43:1219-30. This task uses an innovative go no go design probing the CCaPS that incorporates negative feedback (too slow) into some trials. Hypo-activation of right dorsal and medial prefrontal cortex activation for errors and negative feedback is related to depressive illness. Dorsal rostral cingulate hypoactivation for events immediately subsequent to error and negative feedback trials is related to recurrence of illness.

105. Kikuchi T, Miller J, Schneck N, Oquendo MA, Mann JJ, Parsey RV, et al. Neural responses to incongruency in a blocked-trial Stroop fMRI task in major depressive disorder. J Affect Disord. 2012;143: 241-7. This is one of the largest studies of MDD $(n=42)$ using the Stroop task to probe the CCaPS. The work shows prominent hypo activation in MDD in frontal-parietal, limbic, and subcortical areas for the standard incongruent-congruent contrast.

106. Henriques J, Glowacki JM, Davidson RJ. Reward fails to alter response bias in depression. Abnorm Psychol. 1994;103:460-6.

107. Henriques J, Davidson RJ. Decreased responsiveness to reward in depression. Cogn Emot. 2000;14:711-24.

108. Leibenluft E, Rich BA, Vinton DT, Nelson EE, Fromm SJ, Berghorst LH, et al. Neural circuitry engaged during unsuccessful motor inhibition in pediatric bipolar disorder. Am J Psychiatry. 2007;164:52-60.

109. Passarotti AM, Sweeney J, Pavuluri MN. Emotion processing influences working memory circuits in pediatric bipolar disorder and attention deficit hyperactivity disorder. J Am Acad Child Adolesc Psychiatry. 2010;49:1064-80.

110. Passarotti AM, Sweeney JM, Pavuluri MN. Differential engagement of cognitive and affective neural systems in pediatric bipolar disorder and attention deficit hyperactivity disorder. J Int Neuropsychol Soc. 2010;16:106-17.

111. Geller B, Luby J. Child and adolescent bipolar disorder: a review of the past 10 years. J Am Acad Child Adolesc Psychiatry. 1997;36:1168-76.

112. Guyer AE, Benson B, Choate VR, Bar-Haim Y, Perez-Edgar K, Jarcho JM, et al. Lasting associations between early-childhood temperament and late-adolescent reward-circuitry response to peer feedback. Dev Psychopathol. 2014;1:229-43. One of the first developmental fMRI studies providing evidence that early-life temperament is predictive of altered functioning in rewardrelated regions in late adolescence and early adulthood, both in social and non-social contexts.
113. Gorrindo T, Blair RJ, Budhani S, Dickstein DP, Pine DS, Leibenluft E. Deficits on a probabilistic response-reversal task in patients with pediatric bipolar disorder. Am J Psychiatr. 2005;162: 3.

114. Pizzagalli DA, Goetz E, Ostacher M, Losifescu DV, Perlis RH. Euthymic patients with bipolar disorder show decreased reward learning in a probabilistic reward task. Biol Psychiatry. 2008;64: $162-8$.

115. Dickstein D, Gorrostieta C, Ombao H, Goldberg L, Brazel A, Gable C, et al. Fronto-temporal spontaneous resting state functional connectivity in pediatric bipolar disorder. Biol Psychiatry. 2010;68:839-46.

116. Hariri AR, Brown SM, Williamson DE, Flory JD, de Wit H, Manuck SB. Preference for immediate over delayed rewards is associated with magnitude of ventral striatal activity. J Neurosci Off J Soc Neurosci. 2006;26:13213-7.

117. Christakou A, Brammer M, Rubia K. Maturation of limbic corticostriatal activation and connectivity associated with developmental changes in temporal discounting. Neuroimage. 2011;54: 1344-54.

118. Velanova K, Wheeler ME, Luna B. The maturation of task setrelated activation supports late developmental improvements in inhibitory control. J Neurosci. 2009;29:12558-67.

119. Pulcu E, Trotter P, Thomas EJ, McFarquhar M, Juhasz G, Sahakian BJ, et al. Temporal discounting in major depressive disorder. Psychol Med. 2013;1:1-10.

120. Ahn WY, Rass O, Fridberg DJ, Bishara AJ, Forsyth JK, Breier A, et al. Temporal discounting of rewards in patients with bipolar disorder and schizophrenia. J Abnorm Psychol. 2011;120:911-21.

121. Kessler R, Berglund P, Demler O, Jin R, Merikangas KR, Walters EE. Lifetime prevalence and age-of-onset distributions of DSMIV disorders in the national comorbidity survey replication. Arch Gen Psychiatry. 2005;62:593-602.

122. Luna B, Garver KE, Urban TA, Lazar NA, Sweeney JA. Maturation of cognitive processes from late childhood to adulthood. Child Dev. 2004;75:1357-72.

123. Ernst M, Pine DS, Hardin M. Triadic model of the neurobiology of motivated behavior in adolescence. Psychol Med. 2006;36:299 312.

124. Bjork JM, Smith AR, Chen G, Hommer DW. Mesolimbic recruitment by nondrug rewards in detoxified alcoholics: effort anticipation, reward anticipation, and reward delivery. Hum Brain Mapp. 2012;33:2174-88.

125. Pérez-Edgar K, Kujawa A, Nelson SK, Cole C, Zapp DJ. The relation between electroencephalogram asymmetry and attention biases to threat at baseline and under stress. Brain Cogn. 2013;82: $337-43$.

126. Guyer AE, Nelson EE, Perez-Edgar K, Hardin MG, RobersonNay R, Monk CS, et al. Striatal functional alteration in adolescents characterized by early childhood behavioral inhibition. J Neurosci. 2006;26:6399-405.

127. Guyer AE, Choate V, Detloff A, Benson B, Nelson EE, PerezEdgar K, et al. Striatal functional alteration during incentive anticipation in pediatric anxiety disorders. Am J Psychiatry. 2012;169:205-12.

128.• Nusslock R, Almeida JRC, Forbes EE, Versace A, Frank E, Labarbara EJ, et al. Waiting to win: elevated striatal and orbitofrontal cortical activity during reward anticipation in euthymic bipolar disorder adults. Bipolar Disord. 2012;14:249 60. First study that, using EEG methods, discovered a neurophysiological marker in left frontal activity that prospectively predicts conversion to bipolar I disorder. 